\title{
Insights from assessment type of sexual problems and sexual satisfaction in women: A pilot study
}

\author{
Maria Manuela Peixoto
}

Centro de Investigação em Psicologia para o Desenvolvimento Positivo, Instituto de Psicologia e Ciências da Educação, Universidade Lusíada-Norte, Portugal

\author{
Author note: \\ Correspondence concerning this article should be addressed to \\ Maria Manuela Peixoto \\ Centro de Investigação em Psicologia para o Desenvolvimento Positivo, Instituto de Psicologia e \\ Ciências da Educação, Universidade Lusíada-Norte, Rua Dr. Lopo de Carvalho, 4369 - 006, \\ Porto, Portugal \\ E-mail: mmpeixoto@por.ulusiada.pt
}

\begin{abstract}
Female sexual functioning and satisfaction are impaired by the presence of sexual difficulties. Current study aims to analyze the differences on sexual satisfaction in women according to types of sexual problems (absence of sexual problems, self-perceived and assessed by the FSFI cutoff). A total of 329 women answered to a specific question about presence of self-perceived sexual problems, the Sexual Satisfaction Scale for Women, and the Female Sexual Functioning Index. Main findings revealed that sexually health women had better levels of sexual satisfaction when compared to women who self-report sexual difficulties and women who scored clinical levels in FSFI. Also, women who scored clinical levels in FSFI scored lower on sexual satisfaction compared to women who self-report sexual difficulties. Female sexual satisfaction was negatively affected by sexual difficulties assessed according to the FSFI cut-off. Although with lower impact, self-perceived sexual problems also affect negatively sexual satisfaction in women.
\end{abstract}

Key-words: Assessment; Sexual Functioning; Sexual Problems; Sexual Satisfaction; Women 


\section{Introduction}

Women's sexual problems are highly prevalent (1-5), with incidence estimates over 39\% of women reporting sexual problems $(2,6)$. In addition, female sexual dysfunction has a wellknown negative impact on quality of life (1), well-being (7), psychological adjustment $(8,9)$, sexual health (10), sexual satisfaction (11-14), and dyadic adjustment (15).

Considering women's sexual problems as a relevant health indicator $(5,8,9)$, several valid and reliable self-report tools and structured interviews for assessing women's sexual problems have been developed and can be found in the literature. According to a review conducted by Meston and Derogatis (16), the Golombok Rust Inventory of Sexual Satisfaction [GRISS; (11)], the Brief Index of Sexual Functioning for Women [BISF-W;(17)], the Changes in Sexual Functioning Questionnaire [CSFQ; (18)], the Derogatis Interview for Sexual Functioning [DISF/DISF-SR; (19)], and the Female Sexual Function Index [FSFI; (20)] constitute reliable self-report measures for assessing female sexual (dys)function, with the GRISS (11), the BISF-W (17), and the FSFI (20) allowing to discriminate between women with and without sexual disorders (16). More recently, Velten et al. (21) examined the psychometric properties of a SelfReport Version of the Sexual Interest and Desire Inventory-Female [SIDI-F; (22)], developed or use by clinicians and to assess symptoms related to sexual desire and interest problems in women, with promising results. Self-report instruments are extremely important for providing reliable assessments when time and human resources are limited.

The FSFI (20) is the most extensively used assessment measure for sexual problems in women, in research and academic contexts, clinical settings and clinical trials (23), described as a valuable screening tool for women's sexual dysfunction (24). Given its empirically validated cutoff score for discriminating women with and without sexual dysfunction according to DSM-IVTR criteria (25) and to DSM-5 criteria (26) it is extremely helpful for gynaecological practice (27).

Despite of the extensive use of the FSFI (20) in empirical research, prevalence estimates studies on women's sexual problems relies on a broad range of methodological designs to assess sexual problems. According to a review conducted by Hayes et al. (28), women's sexual problems frequencies have a wide-ranging, mostly because of the due to idiosyncratic questions and time interval selected to assess the main sexual complains. In addition, perceived sexual distress or perceived marked interference in psychosocial functioning are often dismissed in these studies. Thus, empirical data revealed that about 29 to $58 \%$ of women experienced distress as a consequence of a sexual complain $(29,30)$. In this sense, it is not surprising that the literature has found that a cluster of women did not felt distress about their sexual problems (29-32). Nonetheless, recent findings indicated that women with sexual problems more often reported personal, perceived partner, and relational distress (33).

Women's sexual satisfaction can be conceptualized as the experience of satisfaction within the sexual relationship along with the absence of sexual distress (34). Sexual satisfaction can also be understood as a multifactorial construct which involves individual, dyadic and interpersonal dimensions, as sexual functioning levels, sexual activity frequency, dyadic cohesion and adjustment, and relational satisfaction (35). Moreover, sexual satisfaction comprises sexual pleasure, which has been addressed as a sexual right by the World Sexual Health Association. Women's sexual dysfunction has been strongly associated with sexual dissatisfaction $(11,12,14)$, and both play a key role in women's sexual health (10). 
Thus, sexual satisfaction involves emotional, affective and sexual features within an intimate and dyadic relationship. Emotional, affective and sexual aspects include easiness to discuss sex-related, intimate and emotional issues with the intimate partner, comfort to communicate during sex and about sex-related aspects, and matching in terms of sexual beliefs and attitudes, and sexual interests and desires (34). Women with sexual problems struggle to engage in erotic, intimate and sexual conversations with their sexual partners, and often report mismatching their sexual partners in terms of sexual desire and sexual beliefs $(32,36)$, which are expressive indicators of sexual dissatisfaction (37-40). In addition, women's sexual satisfaction implies the absence of distressing personal and relational feelings and emotions (34). Sexually unhealthy women also reported a lack of personal well-being and the presence of relational stress within their intimate relationships (41).

In the clinical context, spontaneous disclosure of symptoms of sexual problems by women is very rare, but when clinicians ask about it, it is still uncommon $(42,43)$, with patients fearful of causing discomfort in the consultation (44). A very recent study highlights the presence of symptoms of sexual dysfunction in individuals with chronic medical conditions in primary and routine care, with $91 \%$ of women reporting consistent symptoms with female sexual dysfunction (45), highlighting the relevance of treating sexual problems and sexual discomfort in a clinical context.

Self-reported sexual satisfaction (46) and sexual functioning (21) are relevant indicators of women's well-being and should be considered in health services. Although sexual satisfaction and sexual distress are often identified and described as closely and negatively related in the research literature on women's sexual health, they are also partially independent dimensions (47). In the present study, we sought to investigate the role of sexual problems' evaluation type on sexual satisfaction among women. More specifically, this study aims to understand how dimensions of sexual satisfaction [assessed by the SSS-W; (34)] are affected by sexual problems identified by the FSFI cut-off score (25) and self-identified sexual problems, compared to sexually healthy women. It is hypothesized that women with sexual problems identified by the FSFI cut-off score (25) will perform significantly worse on all dimensions of sexual satisfaction compared to women with self-identified sexual problems and sexually healthy women. In addition, women with self-identified sexual problems are expected to perform significantly worse compared to sexually healthy women on all dimensions of sexual satisfaction.

\section{Material and Methods}

\section{Procedures}

The project was approved by the Ethics Committee of X University. Once ethical approval and consent to use Portuguese versions of the self-report measures were given, a websurvey was created. Sample collection occur between October 2017 and March 2017, and the web-survey was advertised through mailing-lists from University and Clinical Sexology Societies, and through social networks (e.g., LinkedIn; Facebook). Participants received a full explanation about the study purpose and the link to fulfill the self-report measures. Participants have to read an information sheet and provide their informed consent. Data were collected and archived at the University server, no IP addresses were recorded, no e-mail or other personal information was collected, and no monetary compensation or other incentives were given. The institutional email of the principal investigator was available for any question raised before, during or after the participation Participants read a participant information sheet, where they 
received a full explanation of the current study. Once participants provided their informed consent, they were invited to answer the survey, which took about 12 to 15 minutes.

\section{Participants}

A total of 329 women completed the web-survey, with a mean age of $28.69(\mathrm{SD}=8.78)$. About $83.9 \%$ of women reported 12 or more years of schooling $(n=276), 67.5 \%$ were single $(n$ $=222)$ and $31.0 \%$ were married or live in common law $(n=102)$, and have a mean of relationship length of 63.23 months $(\mathrm{SD}=75.50)$. For the study purpose, the 329 women were assigned to three different groups: (i) with sexual problems assessed by the FSFI cut-off score (25); (ii) with self-identified sexual problems according to a list of main sexual complains (lack of sexual desire, arousal difficulties, lubrication difficulties, sexual pain), but with no reference for sexual difficulties according to the FSFI cut-off score (25); and (iii) without any selfidentified sexual problem and with no reference for sexual difficulties according to the FSFI cutoff score (25). From the 329 women, 56 women scored below 26.55 on the FSFI and were assigned to the FSFI clinical group; 60 women self-identified at least one sexual problem from the sexual complains list, regardless of scoring above the FSFI cut-off score, and were assigned to the self-reported sexual problems group; whereas the remain 213 women were assigned to the sexually healthy group, as no self-perceived sexual problems were identified and FSFI score was above the cut-off suggesting healthy sexual functioning. Table 1 described the sociodemographic characteristics of the sample, according to the three groups of women.

Table 1 - Sociodemographic characteristics of the sample $(N=329)$

\begin{tabular}{|c|c|c|c|c|}
\hline Variables & $\begin{array}{c}\text { Sexually } \\
\text { Health Group } \\
(\mathrm{n}=\mathbf{2 1 3}) \\
\end{array}$ & $\begin{array}{c}\text { Self-reported } \\
\text { Difficulties Group } \\
(\mathbf{n}=\mathbf{6 0})\end{array}$ & $\begin{array}{c}\text { FSFI Cut-off } \\
\text { Difficulties Group } \\
(\mathrm{n}=\mathbf{5 6})\end{array}$ & $\begin{array}{c}\text { Differences between } \\
\text { groups }\end{array}$ \\
\hline Age & $\begin{array}{c}M(\mathrm{SD}) \\
28.99(8.892)\end{array}$ & $\begin{array}{c}M(\mathrm{SD}) \\
27.32(8.05)\end{array}$ & $\begin{array}{c}M(\mathrm{SD}) \\
29.05(9.14)\end{array}$ & $\begin{array}{c}F(2,326) \\
0.90, p=.407\end{array}$ \\
\hline $\begin{array}{c}\text { Educational Level (years) } \\
0 \text { to } 9 \\
9 \text { to } 12 \\
12 \text { or more }\end{array}$ & $\begin{array}{c}\mathrm{n}(\%) \\
1(0.5) \\
31(14.6) \\
181(84.9)\end{array}$ & $\begin{array}{c}\mathrm{n}(\%) \\
- \\
12(20.0) \\
48(80.0)\end{array}$ & $\begin{array}{c}\mathrm{n}(\%) \\
- \\
9(16.1) \\
47(83.9)\end{array}$ & $\begin{array}{c}\chi^{2}(2) \\
.33 \\
p=.850\end{array}$ \\
\hline $\begin{array}{c}\text { Civil Status } \\
\text { Single } \\
\text { Married/Common Law } \\
\text { Divorced/Separated/Widow }\end{array}$ & $\begin{array}{l}141(66.2) \\
70(32.9) \\
2(0.9)\end{array}$ & $\begin{array}{c}44(73.3) \\
14(23.3) \\
2(3.3)\end{array}$ & $\begin{array}{c}37(66.1) \\
18(32.1) \\
1(1.8)\end{array}$ & $\begin{array}{c}.89 \\
p=.641\end{array}$ \\
\hline Relationship length (months) & $\begin{array}{c}M(\mathrm{SD}) \\
68.86(77.59)\end{array}$ & $\begin{array}{c}M(\mathrm{SD}) \\
47.63(54.59)\end{array}$ & $\begin{array}{c}M(\mathrm{SD}) \\
64.66(67.87)\end{array}$ & $\begin{array}{c}F(2,326) \\
2.01 \\
p=.135\end{array}$ \\
\hline
\end{tabular}

\section{Sociodemographic Screening.}

A sociodemographic screening was developed for the study purpose to record personal information, i.e., age, biological sex, educational level, civil status, and relationship length. Additionally, women were asked about current self-perceived sexual problems, which answered according to a yes/no question. After acknowledged current self-perceived sexual problem(s), a list of main sexual problems was presented (e.g., low sexual interest or desire/absence of sexual interest or desire; difficulties reaching orgasm/absence of orgasm; sexual arousal difficulties; lubrication 
difficulties; sexual pain/difficulties related to penetration), and women can choose from it. Female Sexual Functioning Index

The FSFI (20) is a 19-item self-report measure, easily to administered, providing detailed information on sexual function. The measure allows the calculation of specific indexes for each dimension (sexual interest/desire, sexual arousal, lubrication, orgasm, sexual satisfaction, and sexual pain), as well a sexual function index (calculated through the sum of the specific dimensional indexes), with higher scores indicating greater levels of sexual functioning (desire: 1.2-6, arousal: 0-6, lubrication: 0-6, orgasm: 0-6, global satisfaction: 0.8-6, pain: 0-6, total, 2-36). The FSFI presents acceptable test-retest reliability $(r=.79$ to $r=.86)$, good internal consistency (Cronbach's alpha values of .82 and higher), and validity (demonstrated by significant mean difference scores between a clinical and a control group) (20). The Portuguese version also presented good psychometric properties, with good to excellent internal consistency (Cronbach's alpha values between .88 and .93), as well as convergent and discriminant validity (48). Internal consistency level for current study was .95 .

\section{Sexual Satisfaction Scale for Women}

The SSS-W (34) is a 30-item self-report measure, which allow to assess different domains of sexual well-being: contentment, communication, compatibility, personal concern, and relational concern. Both personal and relational concern reflect sexual distress, and their score can be computed according to the mean of both scores. Items are answered according to a 5-point Likert scale, with items that reflect a positive experience of one's sex life being reverse scored (e.g., " $I$ feel content with the way my present sex life is."). Items are then summed to comprise a total score, with higher scores indicating higher levels of sexual satisfaction, and scores range from 30 to 150 for total scale, and from 6 to 30 for each subscale. The SSS-W revealed good reliability, temporal stability, as well as concurrent, convergent and divergent validity (34). Portuguese version reported good psychometric properties, with adequate to excellent internal consistency (Cronbach's alpha values between .69 and .95), as well as convergent, concurrent and discriminant validity (49). The Cronbach's alpha for the present study was .95 .

\section{Results}

To assess the effects of type of sexual problems (self-reported, assessed by the FSFI cutoff, and no sexual difficulties) on Sexual Satisfaction, a Multivariate Analysis of Variance was performed, with Indexes of Sexual Satisfaction [as assessed by the SSS-W subscales; (34)] as dependent variables. Significant main effects were found for type of sexual problems, Wilks' lambda $=0.27, F(22,632)=27.08, p<.001$, partial $\eta^{2}=.49$. As shown in Table 2 , the univariate analysis indicated that significant main effects were found for Contentment, $F(2,326)=104.05, p$ $<.001$, partial $\eta^{2}=.39$, for Personal Concern, $F(2,326)=97.64, p<.001$, partial $\eta^{2}=.38$, for Relational Concern, $F(2,326)=65.85, p<.001$, partial $\eta^{2}=.29$, for Compatibility, $F(2,326)=$ 50.81, $p<.001$, partial $\eta^{2}=.24$, and for Communication, $F(2,326)=15.735, p<.001$, partial $\eta^{2}=$ .09 . 
Table 2 - Means and Standard Deviations for Sexual Satisfaction Scale for Women Subscales according to Women's Groups $(N=329)$

\begin{tabular}{cccccc}
\hline & $\begin{array}{c}\text { Sexually Health } \\
\text { Group }\end{array}$ & $\begin{array}{c}\text { Self-reported } \\
\text { Difficulties Group }\end{array}$ & $\begin{array}{c}\text { FSFI Cut-off } \\
\text { Difficulties Group }\end{array}$ & Total Sample & Univariate tests \\
\hline SSS-W subscales & $M(S D)$ & $M(S D)$ & $M(S D)$ & $M(S D)$ & $F(2,326)$ \\
\hline Contentment & $24.78(3.65)$ & $21.67(4.07)$ & $16.82(3.73)$ & $22.86(4.77)$ & $104.05^{* * *} \eta^{2}=.39$ \\
Communication & $25.85(3.67)$ & $25.95(3.46)$ & $22.73(4.64)$ & $25.33(3.98)$ & $15.73 * * * \eta^{2}=.09$ \\
Compatibility & $26.04(4.00)$ & $25.13(3.98)$ & $19.32(6.22)$ & $24.73(5.08)$ & $50.81^{* * * *} \eta^{2}=.24$ \\
Personal Concern & $25.97(4.53)$ & $20.42(5.62)$ & $16.68(4.76)$ & $23.38(6.03)$ & $97.64^{* * *} \eta^{2}=.38$ \\
Relational Concern & $24.26(5.02)$ & $20.17(5.80)$ & $15.82(4.60)$ & $22.08(6.03)$ & $65.85^{* * * *} \eta^{2}=.29$ \\
\hline
\end{tabular}

Legend: $* * * \mathrm{p}<.001$

According to the Post-hoc Comparisons, with the HSD Tukey-test, the sexually healthy group scored significantly higher on all variables when compared to the FSFI clinical group. The selfreport difficulties group scored significantly higher on all variables when compared to the FSFI clinical group. The sexually healthy group scored significantly higher on all variables except for Compatibility $(p=.496)$ and Communication $(p=.990)$, when compared to the self-report difficulties group (see Figure 1).

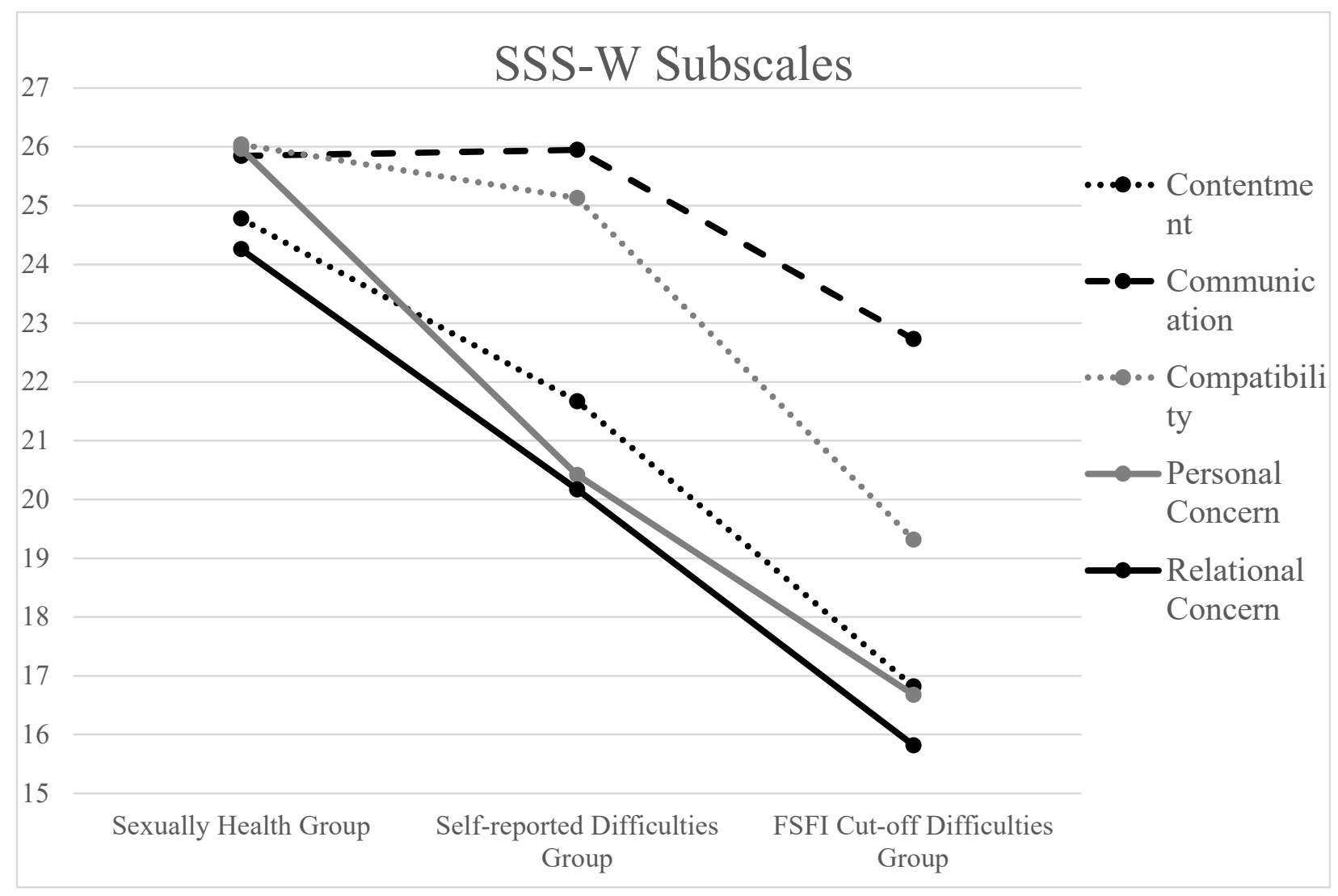

\section{Discussion}

The current study attempted to examine the role of sexual problems assessment type on sexual satisfaction in women. More specifically, this study aims to understand how dimensions of 
sexual satisfaction [assessed by the SSS-W; (34)] are influenced by sexual problems identified by the FSFI cut-off score (25) and self-identified sexual problems, compared to sexually healthy women. Overall, the main results showed that sexual problems assessed by the FSFI cut-off score (25) or self-perceived sexual problems were negatively associated with dimensions of sexual satisfaction in women, which is consistent with the literature on the relationship between sexual dysfunction and sexual satisfaction in women (11-14).

Sexually healthy women reported being more satisfied with their sex lives than the group of women with sexual difficulties according to the FSFI cut-off score, as expected (11-14). Specifically, sexually healthy women reported being more satisfied with their sex lives, more satisfied with their level of communication and sexual compatibility with their sexual partners, and reported worrying less about personal and relationship problems in their sex lives. Previous research has shown that sexually healthy women engage easily in intimate and sexual conversations and have greater compatibility in sexual desire and interest, as well as sexual beliefs and attitudes with their sexual partners $(32,36)$. Sexually healthy women were also found to have higher scores for personal well-being and lack of relationship distress (41), which is consistent with the current findings. A deeper analysis of effect sizes revealed that levels of satisfaction and personal concerns within the sexual relationship were the dimensions with strong differences between women with sexual difficulties according to the FSFI cut-off score and sexually healthy women.

Contrary to expectations, sexually healthy women and women who self-reported the presence of a sexual problem reported differences in contentment with the sexual relationship and in personal and relational concerns, but no differences were found in satisfaction with compatibility and communication within their sexual relationship. In addition, sexually healthy women were more satisfied with their sexual relationship and were less concerned about personal and relational issues related to sexual interaction and satisfaction. Surprisingly, sexually healthy women and women who self-perceived a sexual problem were more satisfied with their level of communication and compatibility with their intimate partners. This particular finding may explain why this group of women achieved good levels of sexual functioning on the FSFI (20). It is possible that feelings of compatibility in terms of desire and attitudes toward sexuality, as well as feelings of satisfaction with sexual communication, act as buffers to levels of sexual functioning. Given this finding, clinicians should promote openness and assertiveness in sexual communication among couples and help couples develop skills to achieve higher levels of sexual compatibility.

Despite the relevance of the current results, the limitations of the study should be acknowledged. This was a pilot study; therefore, no groups of women with clinical diagnoses of sexual dysfunction or women with distressing sexual problems were included in the analyses. Future studies should examine differences in dimensions of sexual satisfaction across a wide range of groups of women with sexual dysfunction, distressing sexual problems, and sexual problems. In addition, an online sample was used for the study, with young women who are well educated and have easy access and comfort in using online platforms. Although the sample size meets the requirements for the statistical procedures performed, future studies should consider larger samples with more heterogeneity, such as sexual orientation, schooling, and relationship duration.

In general, the current findings highlight the role of the way sexual problems are evaluated on the sexual satisfaction experienced by women. Not surprisingly, experiencing sexual 
difficulties, as assessed by an empirically validated cut-off score (25) influenced negatively sexual satisfaction on women. negatively influenced women's sexual satisfaction. A novel finding was the negative impact on women's sexual satisfaction, even when not identified by the FSFI (20). For clinicians working with women and/or couples, it is of utmost importance to explore the definition and individual experience of a sexual problem for women and its impact on the experience of sexual satisfaction. Although preliminary, the current results may present an interesting topic for discussion regarding women's expectations of sexual function and performance.

\section{References}

1. Nappi ProfRE, Cucinella L, Martella S, Rossi M, Tiranini L, Martini E. Female sexual dysfunction (FSD): Prevalence and impact on quality of life (QoL). Maturitas. 2016 Dec;94.

2. McCool ME, Zuelke A, Theurich MA, Knuettel H, Ricci C, Apfelbacher C. Prevalence of Female Sexual Dysfunction Among Premenopausal Women: A Systematic Review and Meta-Analysis of Observational Studies. Sexual Medicine Reviews. 2016 Jul;4(3).

3. McCool-Myers M, Theurich M, Zuelke A, Knuettel H, Apfelbacher C. Predictors of female sexual dysfunction: a systematic review and qualitative analysis through gender inequality paradigms. BMC Women's Health. 2018 Dec 22;18(1).

4. Madbouly K, Al-Anazi M, Al-Anazi H, Aljarbou A, Almannie R, Habous M, et al. Prevalence and Predictive Factors of Female Sexual Dysfunction in a Sample of Saudi Women. Sexual Medicine [Internet]. 2021 Feb 1 [cited 2021 May 14];9(1). Available from: https://doi.org/10.1016/j.esxm.2020.10.005

5. Kammerer-Doak D, Rogers R. Female Sexual Dysfunction. In: Pelvic Floor Disorders [Internet]. Cham: Springer International Publishing; 2021 [cited 2021 May 14]. p. 909-21. Available from: http://link.springer.com/10.1007/978-3-030-40862-6_74

6. Karakaş Uğurlu G, Uğurlu M, Çayköylü A. Prevalence of Female Sexual Dysfunction and Associated Demographic Factors in Turkey: A Meta-Analysis and Meta-Regression Study. International Journal of Sexual Health. 2020 Oct 1;32(4).

7. Rosen RC, Bachmann GA. Sexual Well-Being, Happiness, and Satisfaction, in Women: The Case for a New Conceptual Paradigm. Journal of Sex \& Marital Therapy. 2008 Jun $19 ; 34(4)$.

8. Laumann EO, Paik A, Rosen RC. Sexual Dysfunction in the United States. JAMA. 1999 Feb 10;281(6).

9. Rosen NO, Dubé JP, Corsini-Munt S, Muise A. Partners Experience Consequences, Too: A Comparison of the Sexual, Relational, and Psychological Adjustment of Women with Sexual Interest/Arousal Disorder and Their Partners to Control Couples. The Journal of Sexual Medicine. 2019 Jan;16(1).

10. Abdolmanafi A, Nobre P, Winter S, Tilley PJM, Jahromi RG. Culture and Sexuality: Cognitive-Emotional Determinants of Sexual Dissatisfaction Among Iranian and New Zealand Women. The Journal of Sexual Medicine. 2018 May;15(5).

11. Rust J, Golombok S. The Golombok-Rust Inventory of Sexual Satisfaction (GRISS). British Journal of Clinical Psychology [Internet]. 1985 [cited 2021 May 14];24(1):63-4. Available from: https://pubmed.ncbi.nlm.nih.gov/3971070/

12. Brotto LA, Heiman JR, Goff B, Greer B, Lentz GM, Swisher E, et al. A psychoeducational intervention for sexual dysfunction in women with gynecologic cancer. Archives of Sexual 
Behavior [Internet]. 2008 Apr [cited 2021 May 14];37(2):317-29. Available from: https://pubmed.ncbi.nlm.nih.gov/17680353/

13. Haavio-Mannila E, Kontula O. Correlates of increased sexual satisfaction. Archives of Sexual Behavior [Internet]. 1997 [cited 2021 May 14];26(4):399-419. Available from: https://link.springer.com/article/10.1023/A:1024591318836

14. Leonard LM, Iverson KM, Follette VM. Sexual Functioning and Sexual Satisfaction Among Women Who Report a History of Childhood and/or Adolescent Sexual Abuse. Journal of Sex \& Marital Therapy. 2008 Sep 9;34(5).

15. Peixoto MM, Nobre P. Distressing Sexual Problems and Dyadic Adjustment in Heterosexuals, Gay Men, and Lesbian Women. Journal of Sex \& Marital Therapy. 2016 May $18 ; 42(4)$.

16. Meston CM, Derogatis LR. Validated instruments for assessing female sexual function [Internet]. Vol. 28, Journal of Sex and Marital Therapy. Informa UK Ltd ; 2002 [cited 2021 May 14]. p. 155-64. Available from:

https://www.tandfonline.com/doi/abs/10.1080/00926230252851276

17. Taylor JF, Rosen RC, Leiblum SR. Self-report assessment of female sexual function: Psychometric evaluation of the brief index of sexual functioning for women. Archives of Sexual Behavior [Internet]. 1994 Dec [cited 2021 May 14];23(6):627-43. Available from: https://pubmed.ncbi.nlm.nih.gov/7872859/

18. Clayton AH, Goldfischer ER, Goldstein I, Derogatis L, Lewis-D’Agostino DJ, Pyke R. Validation of the decreased sexual desire screener (DSDS): a brief diagnostic instrument for generalized acquired female hypoactive sexual desire disorder (HSDD). The journal of sexual medicine [Internet]. 2009 Mar [cited 2013 Nov 23];6(3):730-8. Available from: http://www.ncbi.nlm.nih.gov/pubmed/19170868

19. Derogatis LR. The derogatis interview for sexual functioning (Disf/disf-sr): An introductory report. Journal of Sex and Marital Therapy [Internet]. 1997 [cited 2021 May 14];23(4):291-304. Available from: https://pubmed.ncbi.nlm.nih.gov/9427208/

20. Rosen R, Brown C, Heiman J, Leiblum S, Meston C, Shabsigh R, et al. The female sexual function index (Fsfi): A multidimensional self-report instrument for the assessment of female sexual function. Journal of Sex and Marital Therapy [Internet]. 2000 [cited 2021 May 14];26(2):191-205. Available from: https://pubmed.ncbi.nlm.nih.gov/10782451/

21. Velten J, Hirschfeld G, Meyers M, Margraf J. Psychometric Properties of a Self-Report Version of the Sexual Interest and Desire Inventory-Female (SIDI-F-SR). The Journal of Sexual Medicine [Internet]. 2021 May 1 [cited 2021 May 14];18(5):990-5. Available from: https://linkinghub.elsevier.com/retrieve/pii/S1743609521003003

22. Clayton AH, Segraves RT, Leiblum S, Basson R, Pyke R, Cotton D, et al. Reliability and validity of the Sexual Interest and Desire Inventory-Female (SIDI-F), a scale designed to measure severity of female hypoactive sexual desire disorder. Journal of Sex and Marital Therapy. 2006 Mar 1;32(2):115-35.

23. Meston CM, Freihart BK, Handy AB, Kilimnik CD, Rosen RC. Scoring and Interpretation of the FSFI: What can be Learned From 20 Years of use? The Journal of Sexual Medicine. 2020 Jan;17(1).

24. Neijenhuijs KI, Hooghiemstra N, Holtmaat K, Aaronson NK, Groenvold M, Holzner B, et al. The Female Sexual Function Index (FSFI)-A Systematic Review of Measurement Properties. The Journal of Sexual Medicine. 2019 May;16(5).

25. Wiegel M, Meston C, Rosen R. The Female Sexual Function Index (FSFI): Crossvalidation and development of clinical cutoff scores. Journal of Sex and Marital Therapy 
[Internet]. 2005 Jan [cited 2021 May 14];31(1):1-20. Available from:

https://pubmed.ncbi.nlm.nih.gov/15841702/

26. Rincón-Hernández AI, Parra-Carrillo WC, Álvarez-Muelas A, Peñuela-Trujillo C, Rosero

F, Espitia de la Hoz F, et al. Temporal stability and clinical validation of the Spanish version of the female sexual function inventory (FSFI). Women \& Health. 2021 Feb $7 ; 61(2)$.

27. Nappi RE, Albani F, Vaccaro P, Gardella B, Salonia A, Chiovato L, et al. Use of the Italian translation of the Female Sexual Function Index (FSFI) in routine gynecological practice. Gynecological Endocrinology. 2008 Jan 7;24(4).

28. Hayes RD, Dennerstein L, Bennett CM, Sidat M, Gurrin LC, Fairley CK. Risk factors for female sexual dysfunction in the general population: exploring factors associated with low sexual function and sexual distress. The journal of sexual medicine [Internet]. $2008 \mathrm{Jul}$ [cited 2014 Aug 4];5(7):1681-93. Available from:

http://www.ncbi.nlm.nih.gov/pubmed/18410300

29. Mitchell KR, Mercer CH, Ploubidis GB, Jones KG, Datta J, Field N, et al. Sexual function in Britain: findings from the third National Survey of Sexual Attitudes and Lifestyles (Natsal-3). Lancet [Internet]. 2013 Nov 30 [cited 2014 Jul 19];382(9907):1817-29. Available from:

http://www.pubmedcentral.nih.gov/articlerender.fcgi?artid=3898902\&tool=pmcentrez\&re ndertype $=$ abstract

30. Hendrickx L, Gijs L, Enzlin P. Prevalence rates of sexual difficulties and associated distress in heterosexual men and women: results from an Internet survey in Flanders. Journal of sex research [Internet]. 2014 Jan [cited 2014 Aug 4];51(1):1-12. Available from: http://www.ncbi.nlm.nih.gov/pubmed/24164633

31. Burri A, Rahman Q, Santtila P, Jern P, Spector T, Sandnabba K. The relationship between same-sex sexual experience, sexual distress, and female sexual dysfunction. The journal of sexual medicine [Internet]. 2012 Jan [cited 2013 Nov 23];9(1):198-206. Available from: http://www.ncbi.nlm.nih.gov/pubmed/22082180

32. Witting K, Santtila P, Varjonen M, Jern P, Johansson A, von der Pahlen B, et al. Female sexual dysfunction, sexual distress, and compatibility with partner. Journal of Sexual Medicine [Internet]. 2008 Nov 1 [cited 2021 May 14];5(11):2587-99. Available from: http://www.jsm.jsexmed.org/article/S1743609515318786/fulltext

33. Hendrickx L, Gijs L, Enzlin P. Who’s Distressed by Sexual Difficulties? Exploring Associations Between Personal, Perceived Partner, and Relational Distress and Sexual Difficulties in Heterosexual Men and Women. Journal of Sex Research [Internet]. 2019 Mar 24 [cited 2021 May 14];56(3):300-13. Available from: https://www.tandfonline.com/doi/abs/10.1080/00224499.2018.1493570

34. Meston C, Trapnell P. Development and validation of a five-factor sexual satisfaction and distress scale for women: The Sexual Satisfaction Scale for Women (SSS-W). Journal of Sexual Medicine [Internet]. 2005 [cited 2021 May 14];2(1):66-81. Available from: https://pubmed.ncbi.nlm.nih.gov/16422909/

35. Pascoal PM, Narciso I de SB, Pereira NM. What is Sexual Satisfaction? Thematic Analysis of Lay People's Definitions. The Journal of Sex Research. 2014 Jan 1;51(1).

36. Offman A, Matheson K. Sexual compatibility and sexual functioning in intimate relationships. The Canadian Journal of Human Sexuality [Internet]. 2005 Mar 22 [cited 2021 May 14];14(1-2):31-40. Available from: 
https://go.gale.com/ps/i.do?p=AONE\&sw=w\&issn=11884517\&v=2.1\&it=r\&id=GALE\%7 CA138441440\&sid=googleScholar\&linkaccess=fulltext

37. Byers ES, Demmons S. Sexual satisfaction and sexual self-disclosure within dating relationships. Journal of Sex Research [Internet]. 1999 [cited 2021 May 14];36(2):180-9. Available from: https://www.tandfonline.com/doi/abs/10.1080/00224499909551983

38. Cupach WR, Comstock J. Satisfaction with Sexual Communication in Marriage: Links to Sexual Satisfaction and Dyadic Adjustment. Journal of Social and Personal Relationships [Internet]. 1990 Jun 30 [cited 2021 May 14];7(2):179-86. Available from: https://journals.sagepub.com/doi/10.1177/0265407590072002

39. Litzinger S, Gordon KC. Exploring relationships among communication, sexual satisfaction, and marital satisfaction. Journal of Sex and Marital Therapy [Internet]. 2005 Oct [cited 2021 May 14];31(5):409-24. Available from:

https://www.tandfonline.com/action/journalInformation?journalCode=usmt20

40. Timm TM, Keiley MK. The effects of differentiation of self, adult attachment, and sexual communication on sexual and marital satisfaction: A path analysis. Journal of Sex and Marital Therapy [Internet]. 2011 May [cited 2021 May 14];37(3):206-23. Available from: https://www.tandfonline.com/action/journalInformation?journalCode=usmt20

41. Stephenson KR, Hughan CP, Meston CM. Childhood sexual abuse moderates the association between sexual functioning and sexual distress in women. Child Abuse and Neglect [Internet]. 2012 Feb [cited 2021 May 14];36(2):180-9. Available from: /record/2012-06177-001

42. Gott M, Hinchliff S. Barriers to seeking treatment for sexual problems in primary care: A qualitative study with older people. Family Practice [Internet]. 2003 Dec 1 [cited 2021 May 18];20(6):690-5. Available from: https://academic.oup.com/fampra/article/20/6/690/530865

43. Meystre-Agustoni G, Jeannin A, de Heller K, Pécoud A, Bodenmann P, Dubois-Arber F. Talking about sexuality with the physician: Are patients receiving what they wish? Swiss Medical Weekly [Internet]. 2011 Mar 8 [cited 2021 May 18];141(MARCH):13178. Available from: www.smw.ch

44. Kingsberg S. Just ask! Talking to patients about sexual function. Sexuality, Reproduction and Menopause. 2004 Dec 1;2(4):199-203.

45. Pretorius D, Couper ID, Mlambo MG. Neglected sexual dysfunction symptoms amongst chronic patients during routine consultations in rural clinics in the North West province. African Journal of Primary Health Care \& Family Medicine [Internet]. 2021 Apr 28 [cited 2021 May 14];13(1):7. Available from:

http://www.phcfm.org/index.php/PHCFM/article/view/2850

46. Davison SL, Bell RJ, LaChina M, Holden SL, Davis SR. The relationship between selfreported sexual satisfaction and general well-being in women. Journal of Sexual Medicine. 2009 Oct 1;6(10):2690-7.

47. Stephenson KR, Meston CM. Differentiating Components of Sexual Well-Being in Women: Are Sexual Satisfaction and Sexual Distress Independent Constructs? Journal of Sexual Medicine. 2010 Jul 1;7(7):2458-68.

48. Pechorro P, Diniz A, Almeida S, Vieira R. Validação portuguesa do índice de Funcionamento Sexual Feminino (FSFI). Laboratório de Psicologia [Internet]. 2013 Apr 25 [cited 2021 May 14];7(1):33-44. Available from:

http://publicacoes.ispa.pt/index.php/lp/article/view/684 
49. Peixoto MM, Correia A, Gomes HS, Machado PPP. Sexual Satisfaction Scale for Women: a study with Portuguese women with and without sexual difficulties. Sexual and Relationship Therapy [Internet]. 2020 Jul 2 [cited 2021 May 14];35(3):304-19. Available from: https://www.tandfonline.com/action/journalInformation?journalCode $=\mathrm{csmt} 20$ 